\title{
A trilogia de curtas-metragens documentários de Gerson Tavares de 1959
}

\author{
Rafael de Luna Freire*
}

Resumo: Este artigo aborda três curtas-metragens dirigidos pelo cineasta fluminense Gerson Tavares (1926-) e lançados em 1959, intitulados Arte no Brasil de hoje, O grande rio e Brasília, capital do século. Analisamos como esses filmes, especialmente os dois últimos, possuem relações com outros curtas documentários contemporâneos que seriam considerados os deflagradores do Cinema Novo.

Palavras-chave: documentário; Cinema Novo; Gerson Tavares.

Resumen: Este artículo aborda tres cortometrajes documentales dirigidos por el cineasta fluminense Gerson Tavares (1926-) y presentados en 1959, titulados Arte no Brasil de hoje, O grande rio y Brasília, capital do século. Analizamos cómo estas películas, especialmente las dos últimas, mantienen relaciones con otros cortos documentales contemporáneos, los cuales serían después considerados los iniciadores del Cinema Novo brasileño.

Palabras clave: documental; Cinema Novo brasileño; Gerson Tavares.

\begin{abstract}
This article addresses three short documentaries directed by Gerson Tavares (1926- ) and released in 1959, entitled Arte no Brasil de hoje, O grande rio and Brasília, capital do século. We analyze these how these films, especially the last two, keep relations with other contemporary documentaries that would be considered to trigger the Brazilian Cinema Novo movement.

Keywords: documentary; Cinema Novo; Gerson Tavares.
\end{abstract}

Résumé : Cet article traite de trois courts métrages documentaires réalisés par Gerson Tavares (1926), sortis en 1959, et intitulés Arte no Brasil de hoje, O grande rio et Brasília, capital do século. Nous analysons comment ces films, en particulier les deux derniers, entretiennent des relations avec d'autres documentaires contemporains qui peuvent être considérés comme ayant participé au déclenchement du Cinema Novo (Nouveau Cinéma Brésilien).

Mots-clés : documentaire ; Cinema Novo ; Gerson Tavares.

* Universidade Federal Fluminense - UFF, Programa de Pós-Graduação em Comunicação, Departamento de Cinema e Vídeo. 24210-590, Niterói, Brasil. E-mail: rafaeldeluna@hotmail.com

Pesquisa originalmente apresentada sob a forma de comunicação oral durante o XIX Encontro da SOCINE, no âmbito do Seminário Temático "Cinema no Brasil: história e historiografia", realizado na Unicamp, de 20 a 23 de outubro de 2015.

Submissão do artigo: 08 de janeiro de 2016. Notificação de aceitação: 5 de julho de 2016.

Doc On-line, n. 20, setembro de 2016, www.doc.ubi.pt, pp. 5-25. 


\section{Introdução}

Este artigo está diretamente ligado ao projeto "Resgate da obra cinematográfica de Gerson Tavares", financiado através de edital da Secretaria de Estado de Cultura do Rio de Janeiro. Realizado entre 2012 e 2015, a principal ação deste projeto consistiu na restauração do segundo longa-metragem dirigido pelo cineasta fluminense Gerson Tavares, intitulado Antes, o verão (1968), drama estrelado por Jardel Filho e Norma Bengell. O filme corria o risco de se perder devido à degradação das duas únicas cópias sobreviventes da obra, preservadas no acervo da Cinemateca do Museu de Arte Moderna do Rio de Janeiro. Entretanto, durante a sua elaboração o projeto se ampliou com o objetivo de promover um amplo resgate da carreira deste diretor que abandonou o cinema há três décadas, retornando à pintura. Praticamente esquecido desde então, Gerson Tavares continua vivendo, aos 89 anos, em sua casa em Cabo Frio. ${ }^{1}$

No redimensionamento do projeto, foi incluída a ação de digitalização de todos os curtas-metragens dirigidos por Gerson que ainda possuíam materiais preservados. Se os seus dois únicos longas-metragens são ficcionais - além de Antes, o verão, o filme Amor e desamor (1966), estrelado por Leonardo Villar, Leina Krespi e Betty Faria -, todos os seus curtas-metragens são documentários. Dos sete curtas digitalizados e incluídos no DVD duplo "Coleção Gerson Tavares" resultante do projeto, chamam especial atenção os três filmes produzidos, realizados e lançados conjuntamente em 1959, que aqui estou chamando de "trilogia". São eles Arte no Brasil de hoje, Brasília, capital do século e $O$ grande rio. ${ }^{2}$

O objetivo deste artigo é apresentar, contextualizar e analisar esses três filmes, absolutamente esquecidos e amplamente desconhecidos até mesmo dos estudiosos do cinema documentário brasileiro, estando alinhado ao objetivo do projeto de reinscrever o nome de Gerson Tavares na história do cinema brasileiro.

1. Conferir o site do projeto Resgate da obra cinematográfica de Gerson Tavares: http://telabrasilis.com.br/gersontavares.

2. Para uma apresentação geral do projeto e informações sobre todos os curtas-metragens digitalizados, ver Freire, R. L. (2015b), "Relato sobre o projeto Resgate da obra cinematográfica de Gerson Tavares" in Raquel Hallak d' Angelo e Fernanda Hallak d' Angelo (ed.), CineOP: $10^{a}$ Mostra de Cinema de Ouro Preto, Belo Horizonte: Universo Produções, pp. 112-121. O DVD Coleção Gerson Tavares foi finalizado em novembro de 2015, com tiragem de 200 cópias distribuídas gratuitamente para instituições de ensino, preservação e pesquisa. 


\section{Gerson Tavares}

Gerson Tavares e seus filmes estão praticamente ausentes dos livros sobre a história do cinema brasileiro. ${ }^{3}$ Nascido em Alcântara, no município de São Gonçalo, Região Metropolitana do Rio de Janeiro, em 1926, Gerson veio de uma família de baixa renda. Seu pai, um pequeno comerciante, faleceu quando ele ainda era adolescente. Gerson conseguiu concluir o ensino médio e começou imediatamente a trabalhar, mas manteve o sonho de se inscrever na Escola Nacional de Belas Artes.

Em 1947, realizou sua ambição, sendo admitido no curso de pintura da escola, pertencente à então Universidade do Brasil. Pouco depois de formado, em 1951, tentou realizar um novo sonho, que era estudar na Europa. Finalmente conseguiu uma bolsa de estudos que lhe permitiria viver um ano no exterior e partiu para a Europa em 1953. Aprendendo a sobreviver com pouco dinheiro e fazendo vários bicos, Gerson estendeu a duração de sua estada e morou em Lisboa, Madri e Paris. Na capital francesa, conheceu o brasileiro Sergio Montagna, funcionário de uma repartição pública (o Escritório de Propaganda e Expansão Comercial do Brasil), que o "contagiou" com a paixão pela sétima arte. Gerson tornou-se parte de uma geração de jovens de diversas nacionalidades que foram recrutados pelo cinefilia, especialmente entre as décadas de 1940 e 1960, através da experiência parisiense em cineclubes e na Cinemateca Francesa capitaneada por Henri Langlois.

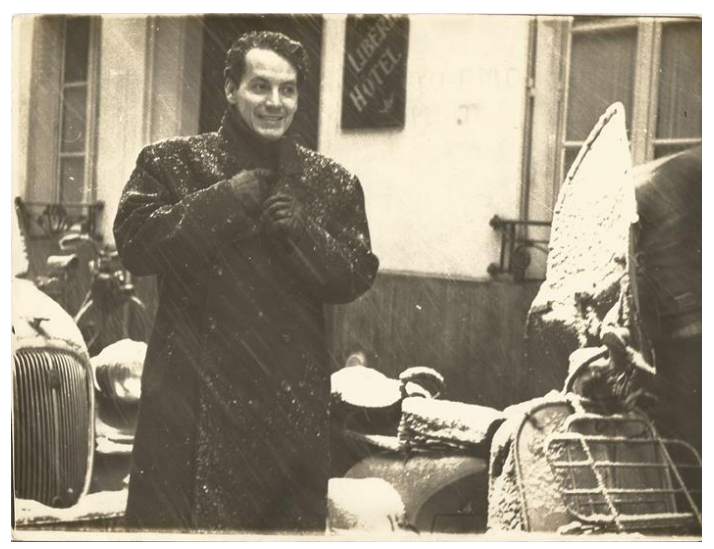

Figura 1. Gerson Tavares em Paris, 1953 (acervo pessoal de Gerson Tavares)

3. As principais exceções são o verbete dedicado a ele no Dicionário de Cineastas Brasileiros (Miranda, 1990: 335-336) e o trecho sobre a criação da Saga Filme no estudo sobre os primeiros filmes de Joaquim Pedro de Andrade (Araújo, 2013: 56). 
Decidido a investir nesse novo campo artístico, o então pintor se matriculou no afamado Centro Sperimentale di Cinematografia, em Roma, realizando, entre 1956 e 1957, o curso de direção. Gerson faz parte do grupo de brasileiros que frequentou a célebre escola de cinema italiana, tendo como colega nomes como os de Trigueirinho Neto e César Mêmolo. ${ }^{4}$ Ainda em Roma, diante da necessidade de sobrevivência financeira, seguiu o conselho de reunir as economias e comprar uma câmera alemã Arriflex $16 \mathrm{~mm}$ e passar a alugá-la como forma de garantir uma renda para sua subsistência. ${ }^{5}$

Em 1958, sem grandes perspectivas profissionais na Europa, formou uma sociedade com Sérgio Montagna e juntos compraram uma câmera nova Caméflex $35 \mathrm{~mm}$ francesa para levá-la ao Brasil. No Rio de Janeiro, formaram uma produtora, a Saga Filmes, a qual se juntou o vizinho de Montagna em Ipanema, o jovem Joaquim Pedro de Andrade. ${ }^{6}$ Os objetivos da Saga Filmes eram muito pragmáticos: realização de documentários institucionais, jingles, comerciais para televisão, aluguel de equipamentos. Perspectiva semelhante, aliás, a de um dos colegas brasileiros de Gerson em Roma, Cesar Mêmolo, que abriu um São Paulo, também em 1958, sua produtora Lynx Filmes, uma das pioneiras e mais importantes empresas de publicidade cinematográfica do Brasil.

Além de um filmete de propaganda para a tradicional casa importadora Lidador, o primeiro trabalho da Saga Filmes foi um filme institucional. Utilizando emprestado o endereço da produtora de Nelson Pereira dos Santos, a Saga Filmes venceu um edital público para realizar o documentário A Petrobrás prepara seu pessoal técnico (1958), dirigido por Gerson e com Joaquim Pedro como assistente de direção. ${ }^{7}$

4. Diversos cineastas brasileiros estudaram no Centro posteriormente, como Luís Sérgio Person, Paulo César Saraceni e Gustavo Dahl, entre outros. Ver Rodrigues, L. (2014), "Proposta de história" in Aída Marques e Luciana Rodrigues (ed.). Cadernos do Forcine. Rio de Janeiro: Fórum Brasileiro de Ensino de Cinema e Audiovisual, pp. 38-39.

5. Informações retiradas de diversas entrevistas do autor com Gerson Tavares, entre $2012 \mathrm{e}$ 2015. Ver também Freire, R. L. (2015a), "Quem é Gerson Tavares?" in Raquel Hallak d'Angelo e Fernanda Hallak d'Angelo (ed.), CineOP: $10^{a}$ Mostra de Cinema de Ouro Preto, Belo Horizonte: Universo Produções, pp. 105-109.

6. Araújo, op. Cit., p. 56-57.

7. Filme incluído no DVD Coleção Gerson Tavares. 


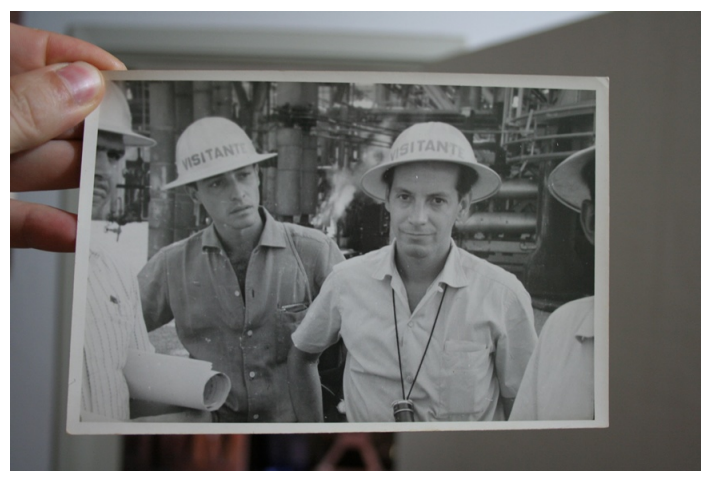

Figura 2. Joaquim Pedro de Andrade e Gerson Tavares nas filmagens de A Petrobrás prepara o seu pessoal técnico, em 1958 (acervo pessoal de Gerson Tavares)

Naquele mesmo ano, um colega italiano de Gerson, o fotógrafo Gianpaolo Santini, já tinha vindo ao Brasil (e passado a viver no apartamento do amigo brasileiro), tendo feito a direção de fotografia de A Petrobrás prepara seu pessoal técnico. Santini viera da Europa com a iniciativa de propor uma sociedade a Gerson na produção de três curtas-metragens sobre o Brasil. Ele faria a fotografia e entraria com filme virgem colorido, enquanto Gerson dirigiria e viabilizaria a produção. Um ficaria com os direitos de exploração do filme no exterior e outro no país. Diante do interesse internacional sobre o Brasil, a ideia seria fazer três filmes que mostrassem o Brasil do passado, do presente e do futuro.

Após algumas conversas, chegaram a uma definição sobre os filmes. $\mathrm{O}$ Brasil do passado seria representado por $O$ grande rio, que reproduziria uma viagem que o próprio Gerson já tinha feito em 1949, quando era estudante de pintura, acompanhando o rio São Francisco da região Nordeste ao Sudeste do Brasil, mostrando o interior autêntico e atrasado do país. O Brasil do presente seria refletido por Arte no Brasil de hoje, que se concentraria na obra de artistas brasileiros contemporâneos então no auge de suas carreiras: o urbanista Lúcio Costa, o arquiteto Oscar Niemeyer, o pintor Cândido Portinari, o paisagista Burle Marx e o escultor Bruno Giorgi. Eram artistas que garantiam visibilidade internacional à arte brasileira no final da década de 1950, configurando a imagem de um país que ingressava na vanguarda da arte mundial. O Brasil do futuro, por sua vez, estaria em Brasília, capital do século, documentário sobre a arrojada construção da nova capital do país que inspirava admiração e surpresa em todo o mundo. 


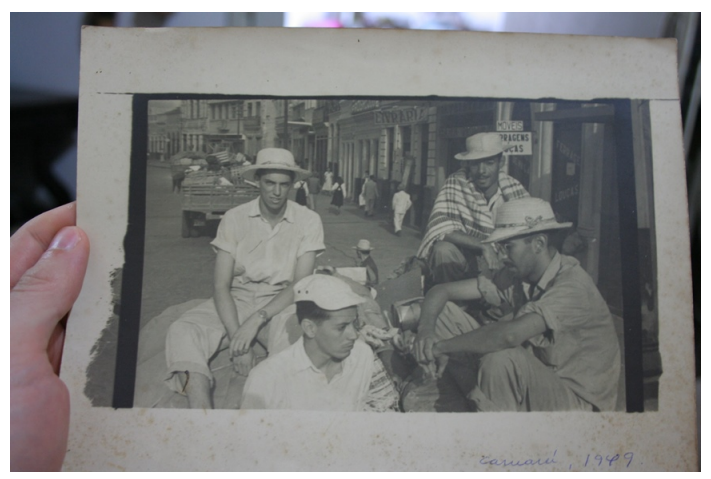

Figura 3. Gerson Tavares, José Ávila da Silveira, Paulo Hiss e Plínio Lopes Cypriano em foto tirada por Fernando Pamplona, todos estudantes da Escola Nacional de Belas Artes. Viagem Recife-Juazeiro-Belo Horizonte-Rio, em 1949, que inspirou o filme $O$ grande rio (acervo pessoal Gerson Tavares)

Desejoso de dirigir os três filmes sem dividir a função com seus dois outros sócios, Gerson saiu da Saga Filmes e encontrou um produtor no jovem Ruy Pereira da Silva. Como Gerson, Ruy também tinha vivido na Europa, mas com o intuito de se preparar para a carreira diplomática, tendo sido outro que descobriu a paixão pelas sétima arte na Cinemateca Francesa. Fascinado por cinema e incentivado por Langlois, Ruy retornou ao Rio de Janeiro com o intuito de criar uma cinemateca na cidade. E, de fato, em 1955 ele fundou o Departamento de Cinema do Museu de Arte Moderna do Rio de Janeiro futura Cinemateca do MAM. Bem relacionado e capaz de travar bons contato com os membros da Federação Internacional de Arquivos de Filmes (FIAF), com executivos dos estúdios de Hollywood e funcionários do setor diplomático, Ruy foi o mentor e organizador do extraordinário Festival "A História do Cinema Americano", em 1958, mas brigas internas o afastaram da Cinemateca do MAM, que passou a ser dirigida pelo crítico José Sanz. No final de 1958, decidido a "fazer cinema", Ruy criou uma produtora, a Procine (constituída oficialmente somente em 1960), para produzir os três curtas propostos por Gerson que seriam seu primeiro projeto. Utilizando seus bons relacionamentos, Ruy conseguiu viabilizar a produção simultânea dos três curtas entre 1958 e $1959 .^{8}$

8. Entrevistas do autor com Ruy Pereira da Silva, em 2015. Sobre o papel de Ruy na criação da Cinemateca do MAM, ver Quental, J. L. A. (2010), A preservação cinematográfica no Brasil e a construção de uma cinemateca na Belacap: a Cinemateca do Museu de Arte Moderna do Rio de Janeiro, Niterói: Dissertação de Mestrado, Universidade Federal Fluminense, pp. 85125 . 
Arte no Brasil de hoje, Brasília, capital do século e $O$ grande rio foram exibidos pela primeira vez no Auditório Mesbla, às $10 \mathrm{~h} 30$ do dia 9 de setembro de 1959, conforme atesta um livro de assinaturas mantido por Ruy Pereira da Silva ${ }^{9}$. O produtor promoveu inúmeras sessões para convidados nas semanas seguintes - no Cinema Riviera, no auditório da Embaixada dos EUA e na cabine da United Artists, por exemplo - havendo grande repercussão quando foi anunciada a conquista da medalha de ouro de melhor filme por $O$ grande rio no I Certamen Internacional de Cine Documental Ibero-Americano y Filipino de Bilbao, na Espanha. ${ }^{10}$

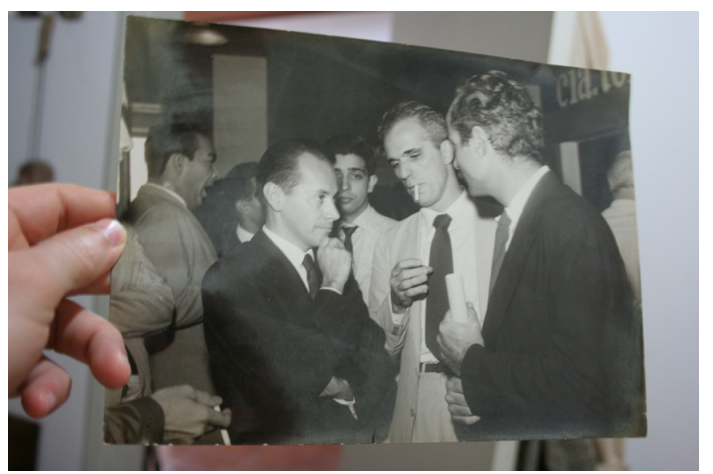

Figura 4. Gerson Tavares na sessão de estreia no auditório Mesbla, em setembro de 1959 (acervo pessoal de Gerson Tavares).

9. Esse livro de assinatura faz parte do acervo pessoal de Ruy Pereira da Silva, residente no Rio de Janeiro.

10. Conforme depoimento de Ruy Pereira da Silva, O grande rio foi indicado pelo Itamaraty para representar o Brasil nesse festival, realizado entre 3 e 9 de outubro de 1959. Uma cópia do filme foi enviada de Roma para a Espanha e Ruy foi noticiado através de carta sobre a premiação em Bilbao. Devido às festas de final de ano, somente em 21 de janeiro de 1960 foi organizada uma cerimônia na Embaixada da Espanha para a entrega da Medalha de Ouro ao produtor e diretor brasileiros. 


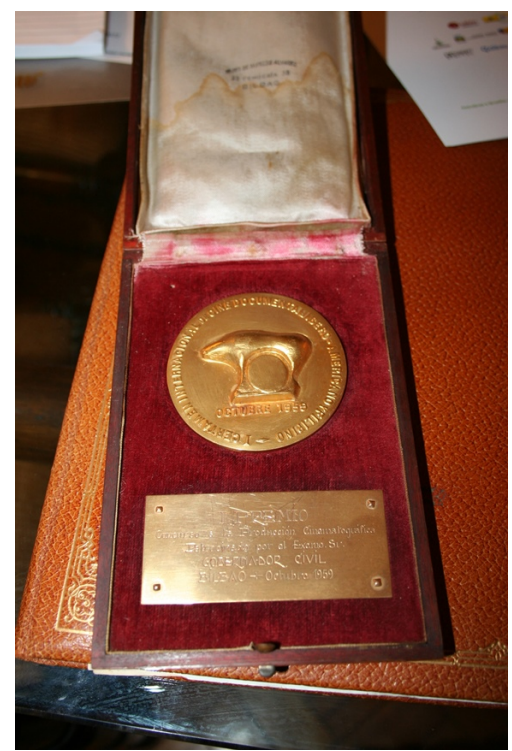

Figura 5. Medalha de Ouro conquistada por $O$ grande rio (acervo pessoal de Ruy Pereira da Silva, foto do autor, 2015).

Enquanto Arte no Brasil de hoje se aproxima mais do formato de documentário educativo tradicional, especificamente do gênero filme sobre arte, exaltando os feitos de grandes artistas nacionais - tendo sido encomendadas, inclusive, versões em inglês, francês e espanhol para distribuição internacional pelo Itamaraty ${ }^{11}$ - nos interessa olhar mais detidamente os filmes $O$ grande rio e Brasília, capital do século. Acreditamos que esses dois curtas-metragens de Gerson Tavares devem ser analisados especificamente no seu contexto histórico, marcado pelo lançamento de outros curtas-metragens brasileiros que renovaram o gênero documentário, revelaram uma nova geração de cineastas, e foram influências fundamentais para a emergência do Cinema Novo. Refirome a filmes como Um dia na rampa, de Luís Paulino dos Santos, e $O$ poeta do Castelo e $O$ mestre dos Apipucos, ambos de Joaquim Pedro de Andrade, e, especialmente, Aruanda, de Linduarte Noronha, e Arraial do Cabo, de Paulo Cezar Saraceni e Mário Carneiro, todos eles lançados entre 1959 e 1960.

11. Ver Unesco (1966), Dix ans de films sur l'art (1952-1962). 1. Peinture et sculpture. Paris: Unesco, p.161. 


\section{A Bossa Nova e a Bossa Novíssima}

A relação dos filmes de Gerson Tavares com esse conjunto de curtasmetragens documentários brasileiros não se baseia apenas no fato de terem sido filmados e lançados no mesmo momento histórico. Ainda em 1960, o jovem crítico e cineasta Glauber Rocha agrupou essas obras em seu artigo "Documentários: Arraial do Cabo e Aruanda", publicado no Jornal do Brasil. Nesse texto, iniciado com a frase "o documentário brasileiro também não existe", Glauber apontava o que seriam os "primeiros sinais de vida" do gênero no cinema brasileiro. O crítico descrevia esse tardio nascimento do documentário como parte de um animado surto iniciado a partir dos longas-metragens de Trigueirinho Neto, Nelson Pereira dos Santos, Roberto Santos e Roberto Farias, entre outros, e dos curtas já citados de Paulino, Noronha, Saraceni e Carneiro, Joaquim Pedro, "Gerson Tavares etc." (Rocha, 1960b).

Em 1961, o mesmo Glauber escreveu um novo artigo em que voltava a alinhar o filme de Gerson a esse novo cinema brasileiro que ele definia e destacava:

O cinema brasileiro ganha este nome: Lima Barreto com seus documentários e $O$ cangaceiro, Nelson Pereira dos Santos com Rio 40 graus e Walter Hugo Khoury com Na garganta do diabo são três nomes ativos que romperam as barreiras tímidas do colonialismo cultural, arrancaram prêmios e despertaram atenções da crítica. Antes, um documentário de Gerson Tavares, $O$ grande rio, também desviou olhares para o selvagem Brasil. Agora, a dupla Saraceni e Mário Carneiro (Rocha, 1961).

Um texto escrito em 1962 pelo crítico e cineclubista Cosme Alves Netto - futuramente curador da Cinemateca do MAM -, dedicado a fazer um "esboço histórico" do Cinema Novo, também incluiu Gerson naquele movimento marcado pela renovação temática e crítica social. Na cronologia de Cosme, o ano de 1959 teria sido marcado por filmes como Aruanda e Um dia na rampa, exibidos apenas em cineclubes e cinematecas, sem maior difusão comercial. Além deles, $O$ solitário dos Apipucos [sic] e $O$ poeta do Castelo, centrados nas figuras de Gilberto Freyre e Manuel Bandeira, e mais um quinto curtametragem: "Já Gerson Tavares prefere a natureza por personagem e sobe o São Francisco, de lá retornando com $O$ grande rio, mais tarde prêmio internacional de curta-metragem no exterior, enquanto no Brasil o público continua sem conhecê-lo" (Alves Netto, s.d. [c.1962]).

No contexto do início dos anos 1960, o prêmio em Bilbao para $O$ grande rio foi incluído por críticos cinematográficos como Glauber e Cosme numa trajetória de crescente visibilidade internacional conquistada pelo cinema brasileiro, que ia da Palma de Ouro de O cangaceiro (1954), de Lima Barreto, até 
a participação ou premiação de outros longas-metragens brasileiros em festivais estrangeiros: $O$ grande momento (1958), de Roberto Santos, em Santa Margarida Ligure, Na Garganta do Diabo (1960), de Walter Hugo Khouri, em Mar Del Plata, Cidade ameaçada (1960), de Roberto Farias, em Cannes. ${ }^{12}$

Particularmente em relação aos curtas-metragens, esses títulos recentes representariam na visão de alguns críticos e cineastas uma renovação do filme documentário brasileiro, marcados por um olhar crítico para a realidade brasileira que se diferenciaria da visão tradicional e oficialesca de documentaristas como Primo Carbonari, Isaac Rozemberg ou Jean Manzon, cuja produção em grande parte ainda se aproximava do que Paulo Emílio caracterizou, em relação à produção documentária brasileira silenciosa, de rituais do poder e berço esplêndido. ${ }^{13}$ Como apontou Luiz Augusto Rezende (2007: 32):

Esses novos filmes e seus diretores teriam estabelecido uma descontinuidade ético-estética com os padrões e as convenções da tradição anterior, tanto por concentrarem-se na "realidade social brasileira", quanto por se livrarem da rigidez formal e do academicismo, iniciando, do ponto de vista da época, uma "revolução realista" na história do cinema brasileiro.

Entretanto, o cinema de Gerson Tavares, inicialmente alinhado a essa ruptura, em pouco tempo seria esquecido, sobretudo em comparação com o mais célebre conjunto de curtas-metragens documentários citados anteriormente. Se em 1960 interessava alinhar $O$ grande rio - e sua premiação internacional - a um novo cinema brasileiro que surgia, pouco depois o mesmo Glauber Rocha trataria de separar "o joio do trigo", buscando distinguir o verdadeiro Cinema Novo do conjunto heterogêneo de filmes dessa primeira fase, por exemplo no artigo "Cinema Novo fase morta (e crítica)", de 1962, e em seu livro "Revisão crítica do cinema brasileiro" (1963). O período entre 1960 e 1962 é quando os curtas de jovens realizadores futuramente identificados ao Cinema Novo também começaram a ganhar prêmios internacionais, especialmente o já citado Arraial do Cabo e o posterior Couro de gato (1962), de Joaquim Pedro de Andrade. ${ }^{14}$

Antes disso, ainda em 1961, o também crítico e cineasta Gustavo Dahl já argumentara que a "a única solução e salvação para o cinema brasileiro" era a juventude (Dahl, 1961). Neste artigo, Dahl prendia-se à analogia criada no ano anterior por Glauber com o campo da música para definir duas escolas

12. Ver Freire, R. L. (2012), "Chanchada, filme policial e Roberto Farias: observações sobre o cinema comercial brasileiro e a nova geração de cineastas" in Hadija Chalupe Silva e Simplício Neto (ed.). Os múltiplos lugares de Roberto Farias, Rio de Janeiro: Jurubeba Produções, p.117.

13. Ver Gomes, P. E. S. (1986), "A expressão social dos filmes documentais no cinema mudo brasileiro (1898-1930)" in Carlos Augusto Calil e Maria Teresa Machado (ed.). Paulo Emílio: um intelectual na linha de frente, São Paulo: Brasiliense, pp. 323-330.

14. Ver Araújo, op. cit., 106-107. 
no cinema brasileiro (Rocha, 1960a). Uma seria a "Bossa Nova", formada por diretores que variavam entre 30 e 35 anos, muitos dos quais lançaram seus primeiros longas-metragens a partir de meados de 1950. A outra seria a "Bossa Novíssima", formada por diretores entre 20 e 30 anos que começavam a lançar seus primeiros filmes, sobretudo curtas, no início da década. Se em 1960 Glauber saudava a possibilidade de encontro entre a Bossa Nova e a Novíssima, a ruptura iminente veio pouco tempo depois. ${ }^{15}$

Em 1959, Gerson, aos 35 anos, situava-se no limite geracional da "Bossa Nova", embora ainda estivesse dirigindo seus primeiros curtas-metragens como os da "Bossa Novíssima". Além disso, tendo vivido cinco anos na Europa, não se encaixava propriamente nos núcleos baiano, paulista ou carioca da Bossa Nova ou Novíssima. É preciso mencionar ainda que Gerson não tinha o suporte financeiro que muitos dos jovens cinemanovistas possuíam - vindos de famílias de classe-média, alguns ainda cursando a universidade e vivendo às custas de seus pais. A necessidade de sobrevivência financeira o levou, inclusive, a abdicar temporariamente do desejo de dirigir filmes, optando por se dedicar durante toda a primeira metade da década de 1960 exclusivamente ao negócio de aluguel de equipamentos cinematográficos que o sustentaria durante toda sua carreira no cinema. ${ }^{16}$

Para além de questões extra fílmicas, quero ainda sugerir algumas aproximações e distanciamentos temáticos e estéticos entre $O$ grande rio e Brasília, capital do século, e o conjunto de curtas-metragens documentários - especialmente Aruanda e Arraial do Cabo - que posteriormente seriam considerados os verdadeiros e principais deflagradores do Cinema Novo.

\section{Aproximações e distanciamentos}

Inicialmente, a trilogia de curtas documentários de Gerson Tavares pode ser aproximada ao chamado "modelo sociológico", conforme definido por Jean-Claude Bernardet, e que teria caracterizado diversos documentários alinhados à primeira fase do Cinema Novo na primeira metade dos anos 1960. Aliás, como também Aruanda e Arraial do Cabo, os três filmes de Gerson possuem uma quase onipresente narração em voz over - realizada por um padre brasileiro residente no Vaticano, uma vez que a finalização dos filmes foi feita em Roma. ${ }^{17}$ Essa narração "regular e homogênea" pode ser enquadrada como a chamada "voz do saber" (Bernardet, 1985: 13), característica da explicação

15. O principal nome de uma "Bossa Nova" que seria plenamente assimilado à "Bossa Novíssima" é o de Nelson Pereira dos Santos, que assumiria um posição de pai ou irmão mais velho dos jovens cinemanovistas.

16. Ver depoimento de Gerson Tavares no documentário Reencontro com o cinema (2014).

17. Depoimento de Gerson Tavares ao autor. 
sociológica que o cineasta faria dos temas, cenários e personagens abordados em seus documentários. Vale ressaltar, porém, que nos filmes de Gerson essa narração - que divide a banda sonora com música e ruídos pós-sincronizados, mas não com entrevistas ${ }^{18}$ - parece atender ao didatismo necessário a filmes que se destinavam a plateias estrangeiras.

Enquanto a narração pode ser um elemento que aproxima filmes como Aruanda e Arraial do cabo da trilogia de Gerson Tavares - aliás, revelam uma continuidade da tradição documentária brasileira de limitação técnica da gravação sincrônica de som e imagem (Rezende, 2007) -, algo que claramente os diferencia é a questão da cor. Apesar do lançamento ainda em 1950 do negativo colorido Eastmancolor pela Kodak, que permitiria o uso da película colorida de forma muito mais prática, econômica e acessível pela indústria de cinema $^{19}$, a filmagem em preto-e-branco permaneceu como padrão da indústria por várias anos, sobretudo no Brasil. ${ }^{20}$

Afinal, o primeiro longa-metragem brasileiro inteiramente colorido só foi realizado em 1953, Destino em apuros, de Ernesto Renani, produção dos estúdios paulistanos da Multifilmes. Como ele, apenas produções que tinham condições de viabilizar a então imprescindível revelação e copiagem em laboratórios estrangeiros podiam fazer uso de negativos coloridos. Consequentemente, no cinema brasileiro da década de 1950 os filmes coloridos viriam a ser associados especialmente a produções ou coproduções internacionais filmadas em terras brasileiras - por exemplo, a comédia romântica Meus amores no Rio (1958), dirigida pelo argentino Carlos Hugo Christensen, filmada com o negativo alemão Agfacolor, ou, sobretudo, o premiado musical Orfeu negro (1959), do francês Marcel Camus, filmado com Eastmancolor. Além de produções que exploravam cenários turísticos como o do Rio de Janeiro, muitos filmes brasileiros coloridos eram ainda documentários "tipo exportação" tidos como exotizantes. Um exemplo marcante é Magia verde (1955), coprodução internacional dirigida pelo italiano Gian Gaspare Napolitano e realizada pelos estúdios paulistanos da Maristela com negativos italianos Ferraniacolor. ${ }^{21}$

18. Segundo depoimento de Gerson Tavares ao autor, o fotógrafo Santini levou nas filmagens um gravador de rolo que serviu para registrar, por exemplo, algumas músicas folclóricas. Essas gravações tentaram ser sincronizadas às imagens em $O$ grande rio.

19. Até então os filmes coloridos hollywoodianos eram, em sua maioria, realizados através do processo Technicolor, que demandava equipamentos e práticas específicas (câmeras mais robustas, iluminação mais intensa, processo de revelação diferenciado).

20. A consolidação do colorido no cinema brasileiro se daria somente na passagem para os anos 1970. Em 1969, dos 21 projetos aprovados pelo Instituto Nacional de Cinema (INC), vinte já eram de filmes a cores. Cf. Ramos, J. M. O. (1983), Cinema, Estado e lutas culturais: anos 60/60/70. Rio de Janeiro: Paz e Terra, p. 63.

21. Apesar dos problemas técnicos, no final da década de 1950 a cor vai se popularizando na produção nacional, mesmo que em pequena proporção: "Recorrendo a negativos europeus, em geral mais baratos, e utilizando o laboratório argentino Curt para o processamento, 
Embora os três curtas-metragens de Gerson Tavares também tenham sido filmados com negativo Ferraniacolor, a situação era bem mais precária do que a que geralmente se dava nos longas-metragens em coprodução internacional. Para a trilogia foram utilizadas, na verdade, sobras de negativo colorido trazidas por Santini, da Europa, que reaproveitou pontas usualmente desprezadas nas filmagens das produções comerciais. ${ }^{22}$ Por serem coloridos, os três filmes foram revelados no laboratório italiano La Microstampa ${ }^{23}$, sendo montados e sonorizados também em Roma ${ }^{24}$. Após a conquista da Medalha de Ouro em Bilbao, cópias feitas em laboratórios brasileiros, em preto e branco, foram encomendadas, trazendo uma cartela inicial destacando a premiação internacional. Ainda assim, a cor ainda era geralmente associada ao grande espetáculo e a um certo cinema comercial, aproximando $O$ grande rio e Brasília, capital do século - sem falar obviamente no mais convencional Arte no Brasil de hoje - mais à qualidade técnica e atualidade tecnológica dos filmes documentários de produtores estabelecidos como os já citados Jean Manzon, Primo Carbonari e Isaac Rozemberg do que à criativa precariedade de Aruanda e Arraial do Cabo.

\section{O Brasil através de um rio}

Abordando mais especificamente cada um dos dois filmes, $O$ grande rio toma o rio São Francisco como meio de conhecer o interior do país, seguindo o mesmo impulso que também moveu diversos cineastas ao longo dos anos 1950 de descobrir o Brasil para os brasileiros através do cinema. Para viabilizar a produção, Ruy Pereira da Silva conseguiu um barco em que a equipe - formada por apenas três pessoas: Gerson, Santini e o assistente Carlos Luiz do Couto - viajou do Sudeste ao Nordeste realizando as filmagens, fazendo o sentido inverso ao da excursão que Gerson participara como estudante. O rio

operacionaliza-se um esquema que permite a feitura de dois a três longas por ano, a partir de 1958". Ver Heffner, H. (2000), "Cor" in Fernão Ramos e Luiz Felipe Miranda (ed.). Enciclopédia do cinema brasileiro, São Paulo: Senac, p.154.

22. Depoimento de Gerson Tavares ao autor. Essas "pontas" eram os últimos metros de negativo que compunham os chassis das câmeras, desprezados para não haver o risco do negativo acabar no meio da filmagem de uma cena importante. A prática de juntar e aproveitar sobras de negativos para viabilizar a filmagem de curtas-metragens não era incomum no cinema brasileiro. O cineasta Antônio Carlos da Fontoura, por exemplo, disse ter usado sobras de negativo colorido de duas produções norte-americanas com o personagem Tarzan, ambas filmadas no Rio de Janeiro, para realizar seu curta-metragem Ver ouvir (1967). Ver Freire, R. L. (2011), Incomodando quem está sossegado: a obra de Plínio Marcos no teatro, literatura e cinema, Rio de Janeiro: Multifoco, p.212.

23. Conforme rótulo das latas originais dos filmes, depositados em 2015 por Ruy Pereira da Silva na Cinemateca do MAM.

24. Nas cópias brasileiras dos três filmes, não há créditos para montagem ou som, apenas para direção, fotografia, roteiro e produção. 
da "unidade nacional", como diz a narração, seus barcos e suas margens servem ao filme como microcosmo de um Brasil autêntico, marcado pela riqueza e pela pobreza, pela diversidade e pela desigualdade: "O Brasil é um país de grandes contrastes", decreta a narração, não deixando de ressaltar a existência de primeira e segunda classe mesmo dentro das típicas embarcações chamadas "gaiolas", numa reprodução do quadro geral de desigualdade econômica e injustiça social do país.

Um trecho do filme merece destaque, quando ele se detém na cidade de Bom Jesus da Lapa, no sertão baiano, às margens do São Francisco. Ao focalizar o antigo santuário localizado nas grutas e galerias de um morro, a narração relata como o local "impressiona pela sua agressividade e imagem caleidoscópica de miséria, doença, crença". Seguem-se imagens de romeiros "ruídos por doenças incuráveis", num lugarejo árido, vazio e desolador. Urubus pousados no telhado de um casebre parecem aguardar o destino aparentemente inevitável de "homens e mulheres [que] fenecem na letargia da miséria", como acrescenta o narrador. Surpreende a representação crua no filme de uma pobreza tão acentuada como a daqueles enfermos miseráveis em busca de curas milagrosas mesmo num filme posterior como $O$ padre e a moça (1966), longa-metragem de Joaquim Pedro de Andrade, a visão de populares marcados por chagas e doenças ainda causaria aversão e impacto.

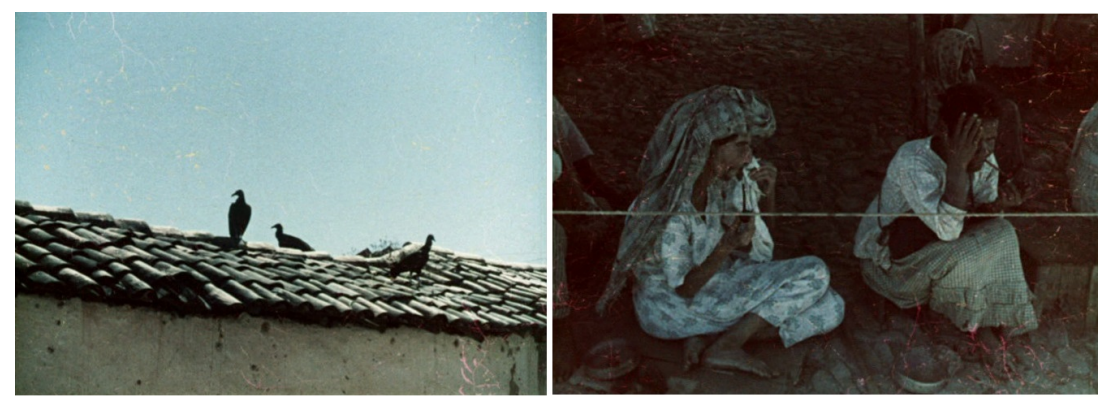

Figuras 6 e 7. Frames de $O$ grande rio (capturadas do DVD Coleção Gerson Tavares)

Encerrando essa sequência, seguem-se dois planos que acompanham um grupo de pessoas - adultos e crianças - caminhando por uma estrada de terra empoeirada e seca. A narração já cessara e, durante os cerca de dezoito segundos desses dois planos em continuidade, ouvimos apenas os passos abafados dos quiçá romeiros, enquanto os acordes lentos e cada vez mais intercalados de um violão vão desaparecendo, como que morrendo lentamente. Mesmo em sua breve duração, é notável a austeridade sonora desses planos em sintonia com a 
aridez das imagens, algo próximo do que seria empregado posteriormente, por exemplo, em Vidas secas (1963), de Nelson Pereira dos Santos. ${ }^{25}$

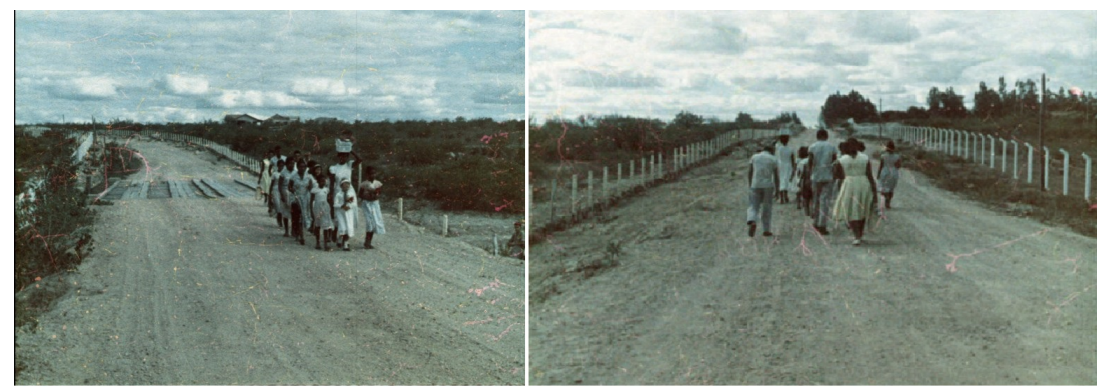

Figuras 8 e 9. Frames de $O$ grande rio (capturados do DVD Coleção Gerson Tavares)

Esse trecho de $O$ grande rio ocorre no filme cerca de dois minutos após uma sequência que revela a riqueza e beleza de festas populares dos franciscanos - a Cavalhada, a Marujada e a Festa do Divino -, expressas, sobretudo, através da música folclórica e das vestes dos seus participantes. ${ }^{26}$

Diante dessa estrutura, percebemos que, em $O$ grande rio, às noções de estagnação e letargia são contrapostas as ideias de movimento e renovação, numa oposição entre economia e cultura/natureza. A primeira é associada ao estado de "completo subdesenvolvimento" da região - conforme dito expressamente pela narração -, revelador também nesse filme da influência do pensamento do Instituto Superior de Estudos Brasileiros que seria marcante no pensamento de cineastas e críticos da época ${ }^{27}$.

Já as noções de movimento e renovação são representadas poeticamente no filme pela ideia de ciclo e sua trajetória contínua e ininterrupta, tanto da natureza quanto dos homens. Ao ciclo do Rio - correndo da nascente ao mar, como mostra a narrativa do documentário - está ligada a vida dos franciscanos que dependem dele para viver, do nascimento à morte. A repetitiva e melancólica canção folclórica, quase um lamento, semelhante à música-tema de Aruanda, que abre e fecha o filme, reforça o caráter cíclico igualmente expresso pelas

25. De 8'27 a 8'45 do filme.

26. Gerson Tavares disse ter dado um "dinheiro" para que se reproduzissem algumas dessas festividades especialmente para a filmagem. Isso parece mais evidente nas exibiçõ̃es dos cavaleiros na Cavalhada do que nas imagens da Festa do Divino, em que há a presença de um grupo amplo de populares acompanhando a procissão. O apelo à "encenação" é mais um dado que aproxima $O$ grande rio da tradição documentária anterior à renovação dos anos 1960.

27. Lembrar, por exemplo, a conclusão impactante do texto "Uma situação colonial?", de Paulo Emílio Salles Gomes, publicado em 19 de novembro de 1960, que definia todo o cinema brasileiro pela mediocridade, "marca cruel do subdesenvolvimento". 
recorrentes imagens da roda do barco à vapor, num filme que se encerra, inclusive, com o fim do dia.

\section{$O$ atraso ao redor da capital do futuro}

Em relação a Brasília, capital do século, Gerson revelou que na exibição especial dos seus três curtas-metragens para o Presidente da República, ocorrida em 29 de setembro de $1959^{28}$, Juscelino Kubitscheck teria se surpreendido por ser o primeiro filme sobre a nova capital em que ele não aparecia em nenhum momento. ${ }^{29}$ De fato, o documentário impressiona por se abster de mostrar quaisquer imagens do então presidente, preferindo se concentrar em dois aspectos da nova capital do país, sua construção, e as pessoas que a constroem.

Numa primeira parte vemos os enormes edifícios e os amplos espaços ainda vazios, com os novos marcos arquitetônicos já podendo ser vislumbrados. A música é pontual, futurística, aparentemente eletrônica. O que anima as imagens são os trabalhadores e seus movimentos vigorosos, reproduzidos em planos em que a câmera é colocada num elevador ou num avião, apequenados diante da monumentalidade das construções. Num segundo momento, em contraste com o anterior, são mostrados os locais onde vivem os candangos e as pessoas que migraram para a região por causa da construção de Brasília. A música é contínua, popular, instrumental.

Gostaria de destacar uma sequência em que filme mostra, pela segunda vez, o que a narração descrevia como a "cidade provisória, chamada Cidade Livre", habitada pelos candangos ao redor de Brasília. ${ }^{30}$ Trata-se de um trecho com menos de dois minutos, com poucas frases ditas pela voz over, intercaladas por silêncios cobertos apenas pela repetitiva música popular. As imagens revelam o contraste das ruas e calçadas cobertas pelo barro vermelho com a moderna e imponente Brasília apresentada pelo filme. Um local onde convivia o arcaico e o moderno, o cavalo e o ônibus, casebres de madeiras e arranha céus de concreto. Nesta sequência, creio haver sentidos nas imagens que sutil, mas propositadamente desafiam a "voz do saber" da narração, não somente deste trecho, mas de todo o resto do filme. Por exemplo, a primeira frase em voz over desta sequência é "Brasileiros de amanhã; para eles o futuro reserva imprevisíveis horizontes", logo seguida de dois planos de um par de meninos

28. Conforme informação do livro de assinaturas de Ruy Pereira da Silva.

29. Ver depoimento de Gerson Tavares no filme Reencontro com o cinema (2014). Ruy Pereira da Silva já possuía uma relação próxima com o presidente da república, que se estreitaria ainda mais posteriormente. Inclusive, JK the encomendaria um filme sobre a inauguração de Brasília, Alvorada de esperança (1961), dirigido e produzido pelo próprio Ruy.

30. De 8:02 a 9:37. 
maltrapilhos, um deles carregando um caixote de engraxate nas costas, caminhando pela rua de terra.

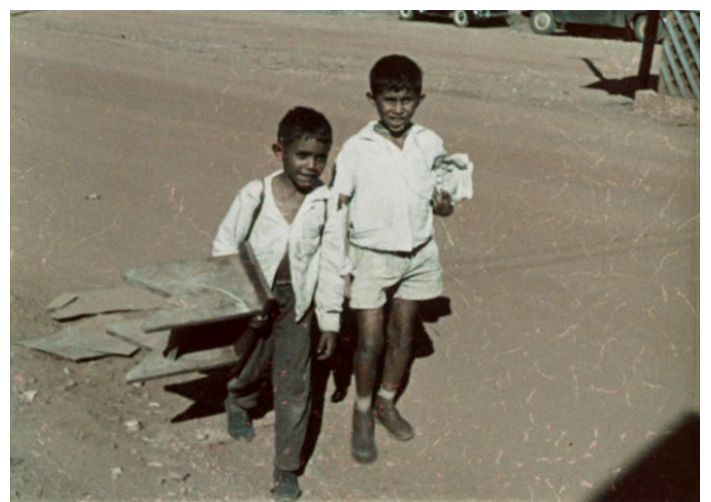

Figura 10. Frame de Brasília, capital do século (capturado do DVD Coleção Gerson

Tavares)

Seguem-se imagens das ruas da cidade provisória, mostrando o vai e vem das pessoas, o comércio, as feiras e o mercado. Neste trecho, a "voz do saber" aparentemente não tem nada para explicar ou dizer, enquanto ouvimos apenas a murmurante música de voz e violão. ${ }^{31} \mathrm{Em}$ seguida, a narração retorna com a frase "Mas aqui problemas sérios que não conhecem ainda resposta" e temos um plano com um lento movimento lateral revelando um grupo de mulheres sentadas lado a lado, de diferentes cores e raças, produzindo um retrato multifacetado da miséria brasileira, sendo que algumas delas encaram diretamente a câmera. O plano seguinte é de um rio-esgoto a céu aberto, onde algumas mulheres lavam roupas e outras, inclusive as mostradas no plano anterior, se limpam e se ensaboam. A narração decreta: "Longe do fragor das máquinas e dos martelos, a natureza auxilia as necessidades dos que vivem o presente". É criado, assim, um contraponto radical às pretensões civilizatórias de Brasília expressas anteriormente na narração e colaborando para um caráter quase acusatório conferido ao olhar das mulheres que romperam, no plano anterior, com a invisibilidade da câmera e do espectador. ${ }^{32}$

Embora de forma não explícita, Brasília, capital do século surpreende por mostrar claramente nessa sequência - mas sem menção na narração - não ape-

31. Como em $O$ grande rio, possivelmente também se tratava de uma música registrada in loco pelo gravador de Santini, pois percebe-se um burburinho de pessoas ao fundo, parecendo ter sido uma canção tocada em uma das feiras livres mostradas no filme.

32. No início da sequência, havia também um breve plano com três crianças, enquadradas frontalmente, olhando para a câmera. 


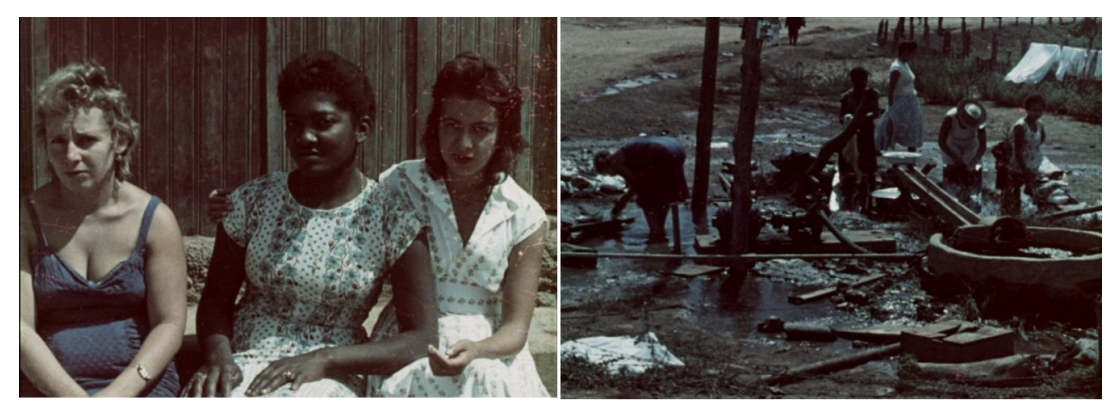

Figuras 11 e 12. Frames de Brasília, capital do século (capturados do DVD Coleção Gerson Tavares)

nas os candangos que migraram para construir a capital, praticamente todos homens, mas também as prostitutas que habitavam as então "cidades provisórias". Era igualmente do suor e do corpo dessas mulheres, lavados ao ar livre, que se erguia a nova capital do Brasil.

Assim como alguns dos curtas documentários eleitos como precursores do Cinema Novo, os dois filmes dirigidos por Gerson Tavares também são sobre espaços físicos, geografias específicas. São sobre Brasília e o rio São Francisco, assim como o de Luís Paulino é sobre Salvador, o de Linduarte sobre Serra Talhada e o de Saraceni e Carneiro sobre Arraial do Cabo. Mas, como eles, o interesse de $O$ grande rio e Brasília, capital do século está nas pessoas que habitam e animam aqueles lugares, num cinema que construía um novo Brasil através de um olhar sobre outros brasileiros, aqueles que tradicionalmente não estavam no centro das telas. $\mathrm{O}$ cinema formalmente acadêmico de Gerson, talvez mais que um cinema de preocupação social, se coloca como um cinema essencialmente humanista, em que mesmo sendo sobre uma cidade ainda em obras, se interessa pelos que já vivem lá, provisória ou improvisadamente.

Se a narração de Brasília, capital do século incialmente afirma que a nova capital era uma "cidade criada para o homem" - expressando as intenções originalmente integradoras e socializantes do projeto de Lúcio Costa e Niemeyer -, ao final o narrador diz: "Acabado o trabalho, Brasília perde a sua própria alma. E morta é em verdade toda cidade sem a presença humana." Nesse sentido, é digno de nota como, em busca do homem, Gerson Tavares talvez tenha sido um dos primeiros cineastas que, ao filmar Brasília, ousou dar as costas à capital e virar sua câmera para fora da monumental cidade piloto. 


\section{Referências bibliográficas}

Alves Netto, C. (c. 1962). Cinema Novo brasileiro: definição e esboço histórico, s.l, s.d. Datilografado. Acervo Cinemateca do Museu de Arte Moderna do Rio de Janeiro.

Araújo, L. C. (2013). Joaquim Pedro de Andrade: primeiros tempos. São Paulo: Alameda.

Bernardet, J. C. (1967). Brasil em tempo de cinema. Rio de Janeiro: Civilização Brasileira.

Bernardet, J. C. (1985). Cineastas e imagens do povo. São Paulo: Brasiliense.

Dahl, G. (1961). Coisas nossas. Jornal do Brasil, 14 Janeiro.

Freire, R. L. (2011). Incomodando quem está sossegado: a obra de Plínio Marcos no teatro, literatura e cinema. Rio de Janeiro: Multifoco.

Freire, R. L. (2012). Chanchada, filme policial e Roberto Farias: observações sobre o cinema comercial brasileiro e a nova geração de cineastas. In $\mathrm{H}$. C. Silva \& S. Neto (ed.). Os múltiplos lugares de Roberto Farias (pp. 108-119). Rio de Janeiro: Jurubeba Produções.

Freire, R. L. (2015a). Quem é Gerson Tavares?. In R. H. d'Angelo \& F. H. d'Angelo (ed.), CineOP: 10 Mostra de Cinema de Ouro Preto (pp. 105109). Belo Horizonte: Universo Produções.

Freire, R. L. (2015b). Relato sobre o projeto Resgate da obra cinematográfica de Gerson Tavares. In R. H. d'Angelo \& F. H. d'Angelo (ed.), CineOP: $10^{a}$ Mostra de Cinema de Ouro Preto (pp. 112-121). Belo Horizonte: Universo Produções.

Gomes, P. E. S. (1986). A expressão social dos filmes documentais no cinema mudo brasileiro (1898-1930). In C. A. Calil \& M. T. Machado (ed.). Paulo Emílio: um intelectual na linha de frente (pp. 323-330). São Paulo: Brasiliense.

Heffner, H. (2000). Cor. In F. Ramos \& L. F. Miranda (ed.). Enciclopédia do cinema brasileiro (pp. 153-154). São Paulo: Senac.

Miranda, L. F. (1990). Dicionário de cineastas brasileiros. São Paulo: Art Editora.

Quental, J. L. A. (2010). A preservação cinematográfica no Brasil e a construção de uma cinemateca na Belacap: a Cinemateca do Museu de Arte Moderna do Rio de Janeiro. Niterói: Dissertação de Mestrado, Universidade Federal Fluminense. 
Ramos, J. M. O. (1983). Cinema, Estado e lutas culturais: anos 50/60/70. Rio de Janeiro: Paz e Terra.

Rocha, G. (1960a). Bossa Nova no cinema brasileiro. Jornal do Brasil, 12: 5. Março.

Rocha, G. (1960b). Documentários: Arraial do Cabo e Aruanda. Jornal do Brasil, 6: 4. Agosto.

Rocha, G. (1961). Arraial, cinema novo e câmara na mão. Jornal do Brasil, Rio de Janeiro, 12 Agosto.

Rocha, G. (1962). Cinema Novo fase morta (e crítica). O Metropolitano, 26 Setembro.

Rocha, G. (1963). Revisão crítica do cinema brasileiro. Rio de Janeiro: Civilização Brasileira.

Rodrigues, L. (2014). Proposta de história. In A. Marques \& L. Rodrigues (ed.). Cadernos do Forcine (pp. 33-55). Rio de Janeiro: Fórum Brasileiro de Ensino de Cinema e Audiovisual.

Silva, R. P. (2015). Entrevistas ao autor, Rio de Janeiro.

Tavares, G. (2012-2015). Entrevistas a autor, Cabo Frio.

Unesco (1966). Dix ans de films sur l'art (1952-1962). 1. Peinture et sculpture. Paris: Unesco.

\section{Filmografia}

A Petrobrás prepara seu pessoal técnico (1958), de Gerson Tavares

Amor e desamor (1966), de Gerson Tavares

Antes, o verão (1968), de Gerson Tavares

Arraial do Cabo (1959), de Paulo Cezar Saraceni e Mário Carneiro

Arte no Brasil de hoje (1959), de Gerson Tavares

Aruanda (1960), Linduarte Noronha

Brasília, capital do século (1959), de Gerson Tavares

Cidade ameaçada (1960), de Roberto Farias

Couro de gato (1962), de Joaquim Pedro de Andrade

Destino em apuros (1953), de Ernesto Renani

Magia verde (1955), de Gian Gaspare Napolitano

Meus amores no Rio (1958), de Carlos Hugo Christensen 
Na garganta do diabo (1960), de Walter Hugo Khouri

O cangaceiro (1954), de Lima Barreto

O grande momento (1958), de Roberto Santos

O grande rio (1959), de Gerson Tavares

O mestre dos Apipucos (1959), de Joaquim Pedro de Andrade

O padre e a moça (1966), de Joaquim Pedro de Andrade

O poeta do Castelo (1959), de Joaquim Pedro de Andrade

Orfeu negro (1959), de Marcel Camus

Reencontro com o cinema (2014), de Rafael de Luna Freire

Um dia na rampa (1960), de Luís Paulino dos Santos

Ver ouvir (1967), de Antônio Carlos da Fontoura

Vidas secas (1963), de Nelson Pereira dos Santos 